\title{
Multi Constrained Optimization model of Supply Chain Based on Intelligent Algorithm
}

\author{
Han Juan \\ School of Management Shanghai University \\ junah432@qq.com
}

Key words: Supply Chain, Intelligent Algorithm, Logistics

\begin{abstract}
In order to research the quality coordination mechanism of logistics service supply chain in condition of bounded rationality, based on research method of logistics supply chain optimization model of evolutionary game theory of intelligent algorithm, evolutionary game model for quality coordination of logistics service supply chain is built and also analyzed. The research results indicate: the factors affecting quality coordination of logistics service supply chain are coordination cost, extraneous income, default cost, excess earning, complaint probability, reputation loss and loss sharing coefficient. By adjusting the values of these parameters, the quality coordination of logistics service supply chain can be effectively facilitated.
\end{abstract}

\section{Introduction}

In service economy age, the proportion of service industry in whole national economy is stepping up, which has promoted the networking, large-scale and branding management of service industry, and the networking development of service enterprises has promoted the generation of service supply chain. As a kind of typical service supply chain, the logistics service supply chain has been put forward by vast scholars and researched persistently. Currently, the researches on logistics service supply chain by most scholars are focused on its intension ${ }^{[1-3]}$, structural feature ${ }^{[3]}$, management method ${ }^{[3]}$, supplier selection ${ }^{[4]}$, coordination mechanism ${ }^{[5,7-13]}$, distribution mechanism $^{[6]}$ and other aspects, while the researches on service quality coordination of logistics service supply chain are relatively less. On the basis of above researches, the paper has analyzed the influence of service quality behavior of joint enterprise in logistics service supply chain on quality coordination and its evolutionary process based on evolutionary game theory, and concluded approach to facilitate balanced quality coordination of logistics service supply chain. The obtained conclusion has certain theoretical value and referential meaning.

\section{Building of evolutionary game model}

According to payoff matrix of game, the expected revenue and average revenue of logistics integrators in strategies of "coordination" and "distribution" respectively are:

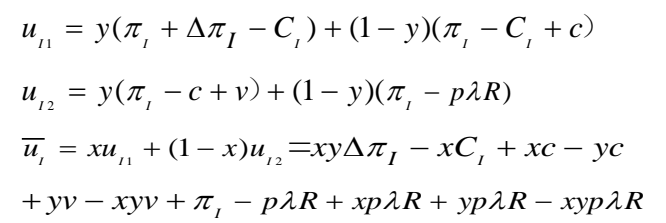

The replicator dynamic equation of logistics integrators is

$\frac{d x}{d t}=x\left(u_{t 1}-\bar{u}_{t}\right)$

$=x(1-x)\left[\left(\Delta \pi_{I}-v-p \lambda R\right) y-C_{I}+p \lambda R+C\right]$

In the same way, the expected revenue and average revenue of logistics subcontractors in strategies of "coordination" and "distribution" respectively are:

$u_{s 1}=x\left(\pi_{s}+\Delta \pi_{s}-C_{s}\right)+(1-x)\left(\pi_{s}-C_{s}+c\right)$

$u_{I 2}=x\left(\pi_{s}-c+v\right)+(1-x)\left[\pi_{s}-p(1-\lambda) R\right]$ 
$\bar{u}_{s}=y u_{s 1}+(1-y) u_{s 2}=x y \Delta \pi_{s}-y C_{s}+y c-x c+x v-x y v$

$+\pi_{s}-p(1-\lambda) R+x p(1-\lambda) R+y p(1-\lambda) R-x y p(1-\lambda) R$

The replicator dynamic equation of logistics subcontractors is

$\frac{d y}{d t}=y\left(u_{s 1}-\bar{u}_{s}\right)$

$=y(1-y)\left\{[\Delta \pi,-v-p(1-\lambda) R] x-C_{s}+c+p(1-\lambda) R\right\}$

Assume $F_{1}(x)=\frac{d x}{d t}, F_{2}(y)=\frac{d y}{d t}$, and $F_{1}(x)=0$, then the

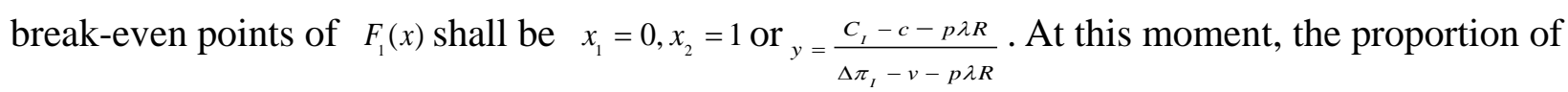
logistics integrators who have adopted coordination strategy in enterprise groups of logistics service supply chain is stable.

In the same way, assume $F_{2}(y)=0$, then the break-even points of $F_{2}(y)$ shall be $y_{1}=0, y_{2}=1$ or $x=\frac{C_{s}-c-p(1-\lambda) R}{\Delta \pi_{s}-v-p(1-\lambda) R}$. At this time, the proportion of logistics subcontractors who have adopted coordination strategy in enterprise groups of logistics service supply chain is stable.

Therefore, according to relevant theory of evolutionary game, on the plane $M=\{(x, y) / 0 \leq x, y \leq 1\}$, five partial break-even points in quality coordination game system of logistics service supply chain respectively are: $O(0,0), A(0,1), \quad B(1,0), C(1,1), D\left(x_{D}, y_{D}\right)$, where

$$
\begin{aligned}
& x_{D}=\frac{C_{s}-c-p(1-\lambda) R}{\Delta \pi_{s}-v-p(1-\lambda) R} \\
& y_{D}=\frac{C_{I}-c-p \lambda R}{\Delta \pi_{I}-v-p \lambda R}
\end{aligned}
$$

\section{Stability analysis of logistics supply chain coordination}

Under Friedman ${ }^{[15]}$, s conclusion, the stability of break-even point of evolution system can be got from partial stability of Jacobian matrix in this system. So according to the replicator dynamic equation of logistics integrators and subcontractors, the Jacobian matrix in this system is

$$
\begin{aligned}
& J=\left[\begin{array}{cc}
\frac{\partial F(x)}{\partial x} & \frac{\partial F(x)}{\partial y} \\
\frac{\partial F(y)}{\partial x} & \frac{\partial F(y)}{\partial y}
\end{array}\right] \\
& =\left[\begin{array}{cc}
(1-2 x)\left[\left(\Delta \pi_{t}-v-p \lambda R\right) y\right. & x(1-x)\left(\Delta \pi_{t}-v-p \lambda R\right) \\
\left.-C_{t}+p \lambda R+c\right] & (1-2 y)\left[\begin{array}{l}
{\left[\Delta \pi_{s}-v-p(1-\lambda) R\right] x} \\
-C_{s}+c p(1-\lambda) R
\end{array}\right] \\
y(1-y)\left[\Delta \pi_{s}-v-p(1-\lambda) R\right] &
\end{array}\right.
\end{aligned}
$$

The determinant value of $J$ is det $J=\frac{\partial F(x)}{\partial x} \frac{\partial F(y)}{\partial y}-\frac{\partial F(x)}{\partial y} \frac{\partial F(y)}{\partial x}$,

And the trace is $\operatorname{tr} J=\frac{\partial F(x)}{\partial x}+\frac{\partial F(y)}{\partial y}$. If the break-even point makes det $J>0$ and $\operatorname{tr} J<0$, the break-even point shall be in partially stable state. The partially stable results of the break-even points in this system are showed in Table 1. 
Table 1 Partial stability analysis of break-even point

\begin{tabular}{cccc}
\hline $\begin{array}{c}\text { Break-even } \\
\text { points }\end{array}$ & det $J$ & TrJ & Results \\
\hline$(0,0)$ & + & - & $\begin{array}{c}\text { Stable } \\
\text { point }\end{array}$ \\
$(0,1)$ & - & - & $\begin{array}{c}\text { Unstable } \\
\text { point }\end{array}$ \\
$(1,0)$ & - & - & $\begin{array}{c}\text { Unstable } \\
\text { point }\end{array}$ \\
& & & $\begin{array}{c}\text { Stable } \\
\text { point } \\
(1,1)\end{array}$ \\
& + & - & $\begin{array}{c}\text { Saddle } \\
\text { point }\end{array}$ \\
\hline$\left(x^{*}, y^{*}\right)$ & - & 0 &
\end{tabular}

From Table 1, it can be known that in five break-even points, only $o(0,0)$ and $C(1,1)$ are stable and they are evolutionary stabilization strategies, which are respectively corresponding to two strategies of integrators and subcontractors (distribution, distribution) and (coordination, coordination).

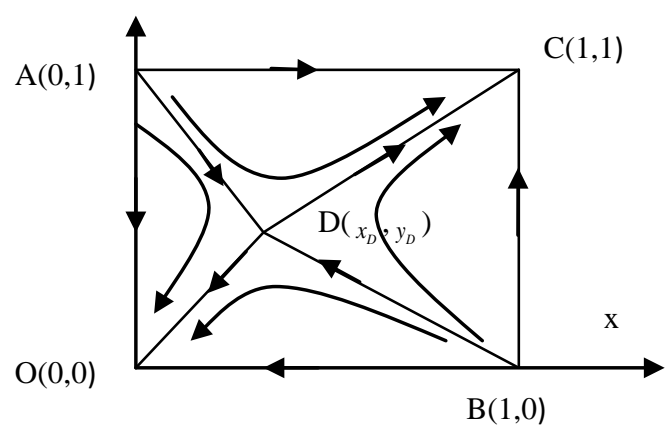

Figure 1 System evolution phase diagram

In order to understand Table 1 better, system dynamic evolution phase diagram (Figure 1) should be combined. Figure 1 describes dynamic evolution process of quality coordination game of integrators and subcontractors. The broken line ADB connected by two unstable break-even points $A(0,1)$ and $B(1,0)$ as well as saddle point $D\left(x_{D}, y_{D}\right)$ constitutes critical line of constrained state of system. When the original state is in ADBC area, the system shall be constrained in break-even point $_{C(1,1)}$, i.e. the integrators and subcontractors in logistics service supply chain shall both adopt "coordination" strategy; when the original state is in ADBO area, the system shall be constrained in break-even point $O(0,0)$, i.e. the integrators and subcontractor shall both adopt "distribution" strategy. The system evolution is a long-term process, so during the evolution the system shall be presented as coexisted state of coordination and distribution strategies.

\section{Influence factors of evolution result}

Combined with phase diagram of system, effect of every parametric variation on system evolution behavior will be discussed below. Figure 1 shows that quality coordination of supply chain of logistics service depends on sizes of area $S_{A D B O}$ of region ADBO and area $S_{A D B C}$ of region. If $S_{A D B O}>S_{A D B C}$, and probability of adopting coordination is bigger than probability of decentralized strategy, system will evolves towards point $C(1,1)$ along route of DC. On the contrary, if $S_{A D B O}>S_{A D B C}$, then system will evolves towards point $\mathrm{O}(0,0)$ along route of DO. If $S_{A D B O}=S_{A D B C}$, then direction of evolution of system is not clear.

From Figure 1, area of region ADBO is as follows: 


$$
S_{A D B O}=\frac{1}{2}\left(x_{D}+y_{D}\right)
$$

According to formula (1), (2) and (3) and Figure 1, several factors affecting evolution of system can be obtained.

\section{Coordination cost}

According to formula (1) and (2), decrease of coordination cost $C_{t}, C_{s}$ will lead to decrease of $x_{D}, y_{D}$. According to formula (3) and phase diagram (Figure 1), saddle point of system $D\left(x_{D}, y_{D}\right)$ will moves towards bottom left, thus resulting in decrease of area $S_{A D B O}$ (in region of $\mathrm{ADBO}$ ) and increase of area $S_{A D B C}$ (in region of $A D B C$ ) simultaneously and probability that system will evolves towards $C_{C(1,1)}$ in overall coordination direction along route of DC will increases. That is to say, the less the coordination cost of integrator and sub-contractor is, the higher the probability that both sides choose coordination strategy is. So, with coordination cost decreasing, probability that integrator and sub-contractor in logistics service supply chain choose coordination strategy will be higher.

\section{Extraneous income coming from breach of contract}

According to formula (1) and (2), decrease of extraneous income $v$ coming from breach of contract will result in decrease of $x_{D}, y_{D}$. According to formula (3) and phase diagram (Figure 1), saddle point of system $D\left(x_{D}, y_{D}\right)$ will moves towards bottom left, thus resulting in decrease of area $S_{A D B O}$ (in region of $A B D O$ ) and increase of area $S_{A D B C}$ (in region of $A D B C$ ) simultaneously and probability that system will evolves towards $C_{(1,1)}$ in overall coordination direction along route of DC will increases. That is to say, the less the extraneous income gained by breaking quality contract by integrator and sub-contractor is, the higher the probability that both sides choose coordination strategy is. To promote quality coordination of LSSC, integrator and sub-contractor should try their best to lower subscription of logistics service between them.

\section{Penalty cost}

According to formula (1) and (2), increase of penalty cost $c$ of different enterprises groups in logistics service supply chain will result in decrease of $x_{D}, y_{D}$. According to formula (3) and phase diagram (Figure 1), saddle point of system $D\left(x_{D}, y_{D}\right)$ will moves towards bottom left, thus resulting in decrease of area $S_{A D B O}$ (in region of $A B D O$ ) and increase of area $S_{A D B C}$ (in region of ADBC) simultaneously and probability that system will evolves towards $C_{(1,1)}$ in overall coordination direction along route of DC will increases. To promote quality coordination of LSSC, integrator and sub-contractor must fix penalty cost on a higher level when they construct quality contract to avoid breach of contract of logistics integrator and sub-contractor.

\section{Excess earnings}

According to formula (1) and (2), increase of excess earnings $\Delta \pi_{1}, \Delta \pi_{s}$ gained by integrator and sub-contractor will result in decrease of $x_{D}, y_{D}$. According to formula （3） and phase diagram (Figure 1), saddle point of system $D\left(x_{D}, y_{D}\right)$ will moves towards bottom left, thus resulting in decrease of area $S_{A D B O}$ (in region of $\mathrm{ABDO}$ ) and increase of area $S_{A D B C}$ (in region of ADBC) simultaneously and probability that system will evolves towards $C_{(1,1)}$ in overall coordination direction along route of DC will increases. If sub-contractor and integrator choose to increase supernormal profit gained through quality coordination strategy, the probability that both sides choose coordination strategy will increase, which will push system to evolve towards overall coordination direction. 


\section{Complaint probability}

According to formula (1) and (2), increase of complaint probability $p$ from customer enterprise will result in decrease of $x_{D}, y_{D}$. According to formula (3) and phase diagram (Figure 1), saddle point of system $D\left(x_{D}, y_{D}\right)$ will moves towards bottom left, thus resulting in decrease of area $S_{A D B O}$ (in region of $\mathrm{ABDO}$ ) and increase of area $S_{A D B C}$ (in region of $\mathrm{ADBC}$ ) simultaneously and probability that system will evolves towards $C_{(1,1)}$ in overall coordination direction along route of DC will increases. If client increases complaint probability to logistics service, it will push the increase of the probability that integrator and sub-contractor choose coordination strategy, which will push system to evolve towards overall coordination direction.

\section{Reputation loss}

According to formula (1) and (2), increase of reputation loss $R$ of integrator and sub-contractor will lead to decrease of $x_{D}, y_{D}$. According to formula (3) and phase diagram (Figure 1), saddle point of system $D\left(x_{D}, y_{D}\right)$ will moves towards bottom left, thus resulting in decrease of area $S_{A D B O}$ (in region of $A B D O$ ) and increase of area $S_{A D B C}$ (in region of ADBC) simultaneously and probability that system will evolves towards $C_{C(1,1)}$ in overall coordination direction along route of DC will increases. If reputation loss created by choice of decentralized strategy by integrator and sub-contractor is greater, it will push the increase of the probability that integrator and sub-contractor choose coordination strategy, which will push system to evolve towards overall coordination direction.

\section{Conclusion}

Realizing quality coordination of logistics service supply chain is an important way to enhance service quality of logistics enterprise and to promote customer satisfaction. As carrier of logistics service, node enterprise in logistics service supply chain is affected by penalty cost, coordination cost, extraneous income, complaint probability, prospective earnings, reputation loss and loss apportionment coefficient when it chooses behavioral strategy on quality. Above parameters must be adjusted well to guarantee that strategy choice of joint enterprise in logistics service supply chain evolves towards coordination direction and restrains itself to strategy (coordination, coordination). Specifically, promote that integrator and sub-contractor can evolve towards direction (coordination, coordination) to essentially improve service quality in logistics service supply chain by establishing some reasonable institutional arrangements, for example, enhancing prospective earnings, lowering coordination cost, signing quality contract, and building fair mechanism and reputation mechanism.

\section{Reference}

[1] He, J., Geng, Y., Wan, Y., Li, S., and Pahlavan, K. (2013). A cyber physical test-bed for virtualization of RF access environment for body sensor network. Sensors Journal, IEEE, 13(10), 3826-3836.

[2] Lv Z, Tek A, Da Silva F, et al. Game on, science-how video game technology may help biologists tackle visualization challenges[J]. PloS one, 2013, 8(3): 57990.

[3] Su T, Wang W, Lv Z, et al. Rapid Delaunay triangulation for randomly distributed point cloud data using adaptive Hilbert curve[J]. Computers \& Graphics, 2016, 54: 65-74.

[4] Jinyu $\mathrm{Hu}$, Zhiwei Gao and Weisen Pan. Multiangle Social Network Recommendation Algorithms and Similarity Network Evaluation[J]. Journal of Applied Mathematics, 2013 (2013). 